Classification

Physics Abstracts

61.72.Mm - 06.60. $\mathrm{Mr}-06.30 . \mathrm{Bp}$

\title{
Automatic Grain Size Measurement in Low Carbon Steels by Image Analysis
}

\author{
Frédéric Le Pennec and Dominique Malewicz \\ SOLLAC, Centre de Recherches et de Développements Métallurgiques, Rue du Comte Jean, \\ Grande Synthe, BP 2508, 59381 Dunkerque Cedex 1, France
}

\begin{abstract}
Résumé. - La caractérisation de la granulométrie des structures des aciers SOLLAC est réalisée par analyse d'images en tant que ressource fiable et reproductible pour l'évaluation et l'amélioration des propriétés mécaniques. La description de la méthode utilisée et ses raisons sont décrites. Lévaluation du logiciel a fait l'objet de validations statistiques. Cette méthode de caractérisation permet d'atteindre des précisions sur la taille de grain, décrite par l'intercept linéaire moyen, de $2 \%$ en valeur relative.
\end{abstract}

\begin{abstract}
Grain size measurement using automatic image analysis is performed on low carbon steels from SOLLAC. This method allows the assessment and the improvement of the mechanical properties of our steels. The questionable reproductibility of manual methods is overcome. The quality of the system has been tested using a statistical approach. It allows to give very accurate results ( $2 \%$ in relative value) of the mean linear intercept, which describes the grain size.
\end{abstract}

\section{Introduction}

In the steel industry the quantification of structures is not a new field of activity. The quality control of steels required for a long time the knowledge of their inclusion content (cleanliness) and of their grain size. Classifications described by standards such as ASTM are commonly used for inspection purpose.

A new goal, far more ambitious, arose with the growing use of metrology means as well as the development of the computational resources: physical modeling of the mechanical properties. This purpose requires knowledge of the physical phenomena occurring during the process as well as the establishment of relationship between structural parameters and mechanical properties. One of them is the Hall-Petch law: $\operatorname{Re}=\mathrm{Ky}(\mathrm{d} \alpha)^{-1 / 2}$ relating the yield strength $\mathrm{Re}$ to the ferrite grain size. Ky depends on the chemical content of the steel and $\mathrm{d} \alpha$ is the mean linear intercept. The intercept method of measurement is one of the standardized method to describe the grain size. Good predictions will therefore be performed if the structural reality like the grain size is accurately measured. Accurate means at least reproductible whatever the kind of structure (ferrite + perlite, granular bainite + ferrite laths. Figs. 1 and 2 ) to be characterized. Image analysis brings new possibilities for grain size measurement. This is one of the key for improving steels' properties. 


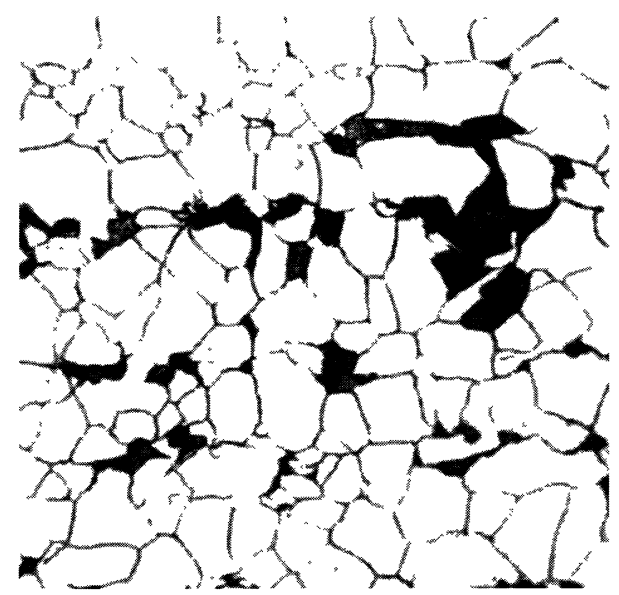

Fig. 1.

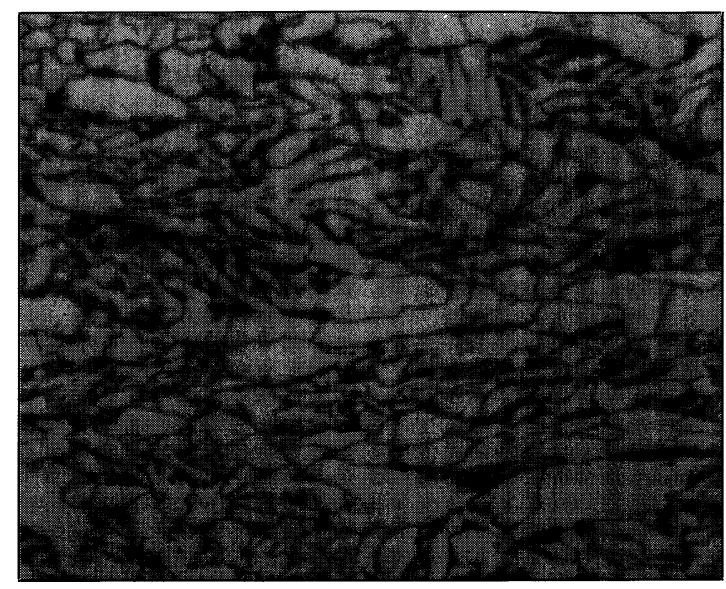

Fig. 2.

Fig. 1. - Ferrite + perlite etched DINO + picral.

Fig. 2. - Granular bainite + ferrite laths.

\section{State of the Art and Requirements}

Manual grain size measurement, whatever the method used (intercept, standard image comparison) is neither accurate (the relative error is greater than 10\%), nor reproductible both between different operators and between two periods of time.

To meet the inspection requirements as well as to be able to use results already obtained manually, Sollac decided to perform automated grain size by measuring the intercept as well as to determine the area percentage of carbide phases. The aim is also to be able to characterize by a unique treatment the whole kinds of structures met in Sollac which are mainly microalloyed steels, low alloyed steels and sometimes almost pure iron.

\section{Image Analysis}

3.1 Metallographic Preparation. - This stage is of first importance. The structure must be polished properly so as to avoid scratches or deep damaged layer. The etchant has to be universal so as to have the same accurate grain depiction whatever the quality of steel and structures met. This depiction must be as far as possible complete and without disturbances (twin boundaries for e.g.). This has been achieved by combining two etchants called Dino and picral. The latter etches the carbide phases whereas the former etches grain boundaries.

3.2 Image Treatment. - The extraction of the carbide phases is performed thanks to a top hat transformation. The image is then multiplied, complemented and added to the initial one (Fig. 3). The binary image obtained by an automatic threshold is conditionally reconstructed after having treated imperfections by thinning, complete pruning and after erasing isolated points (Figs. 4 and 5). The image of the carbide phases is thus obtained and area measurements are performed.

The grain boundaries are emphasized by the multiplication of the result of a top hat transformation (as shown in Fig. 6). This allows the extraction of the thin dark regions by a threshold 


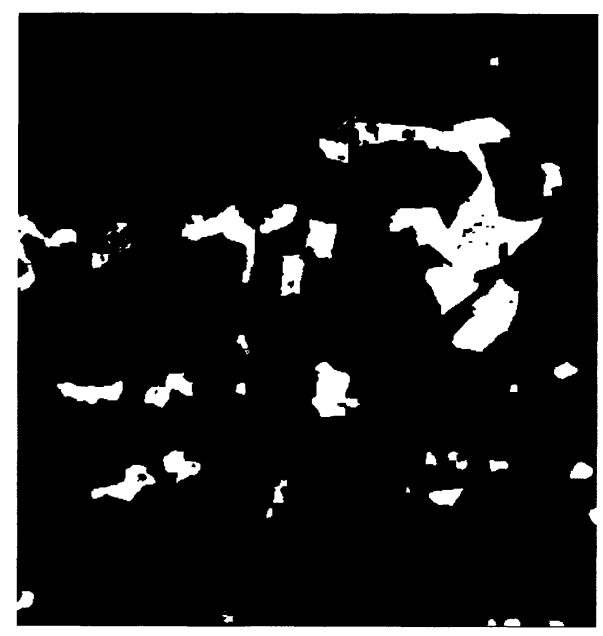

Fig. 3. - Result of the transformed image 1 before threshold for extracting carbides.

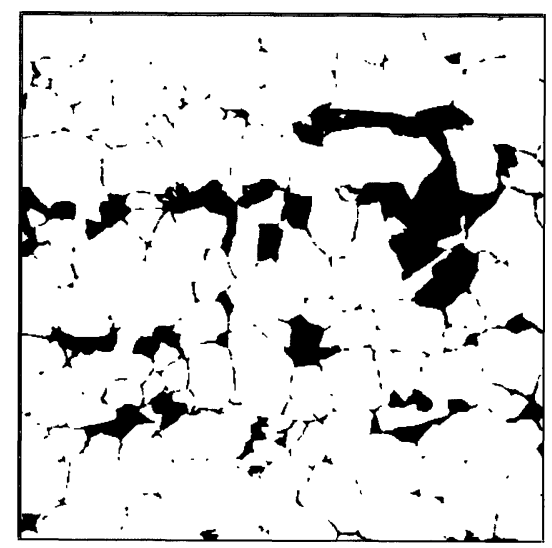

Fig. 4.

Fig. 4. - Threshold of the prior image.

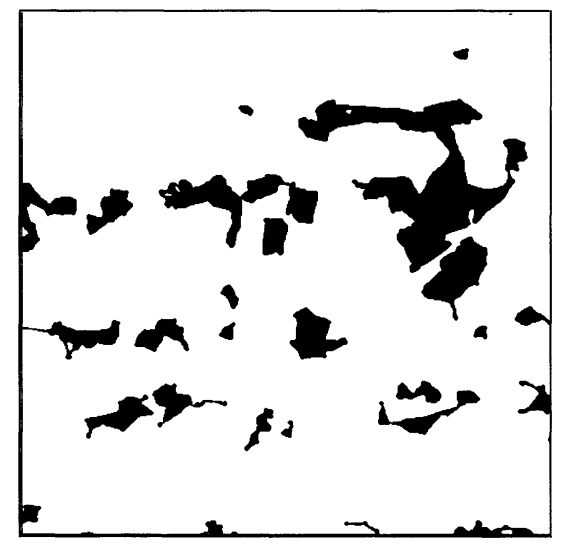

Fig. 5.

Fig. 5. - Reconstruction after thinning and pruning.

performed at a maximum yield. A reconstruction is carried out before the skeletonization (Fig. 7). The small artefacts are suppressed by pruning with a finite number of iterations and small particles are suppressed by a class size treatment after having complemented the image (Fig. 8). The application of a linear grid on the image leads to the linear intercept measurement (Fig. 9).

The commonly used boundary completion is not set since either it was not carried out correctly or it took almost ten minutes for a proper work. The effort was thus held on the preparation and on etching conditions. It led to very satisfactory results. In these conditions, the results are not statistically sensitive to the "miss" of completion. The fact that grain size do not rely on area measurements for which few missing pixels on grain boundaries have a major influence by fusing grains, but on intercept measurements explains partly this result. 


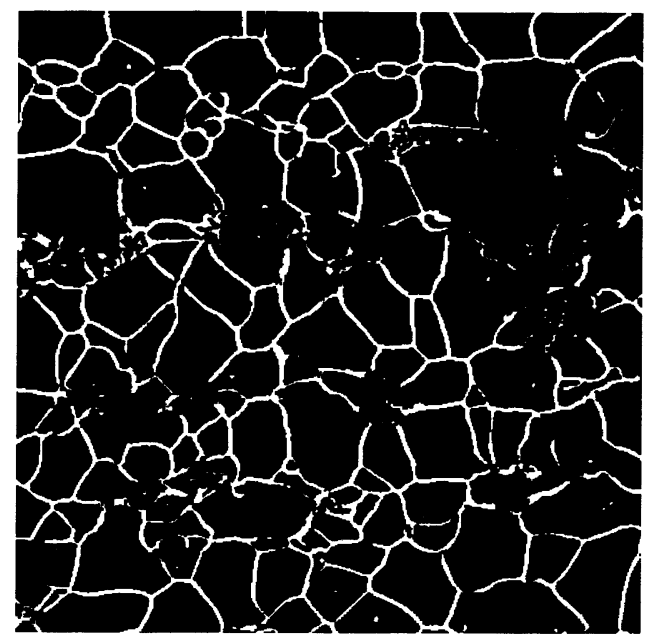

Fig. 6.

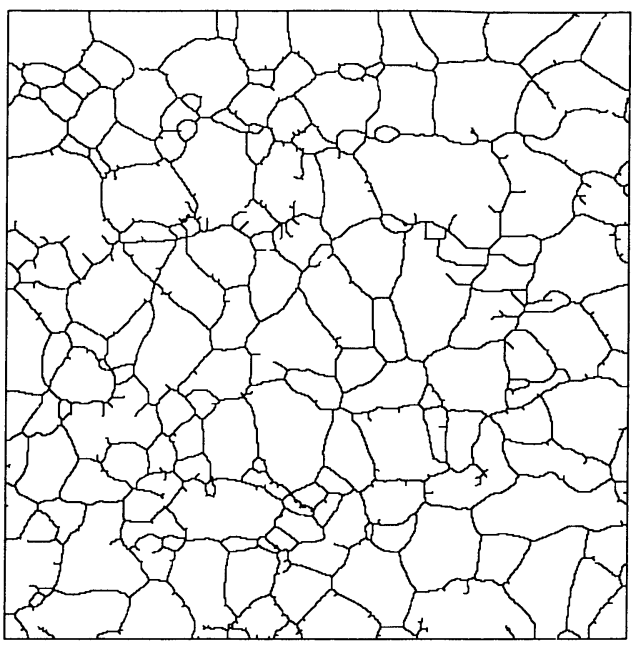

Fig. 7.

Fig. 6. - Multiplication of the top hat transformation.

Fig. 7. - Result of the skeletonization.

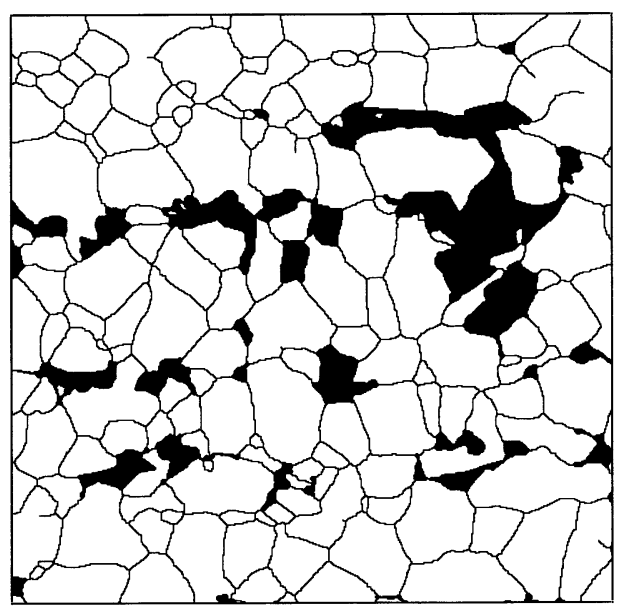

Fig. 8.

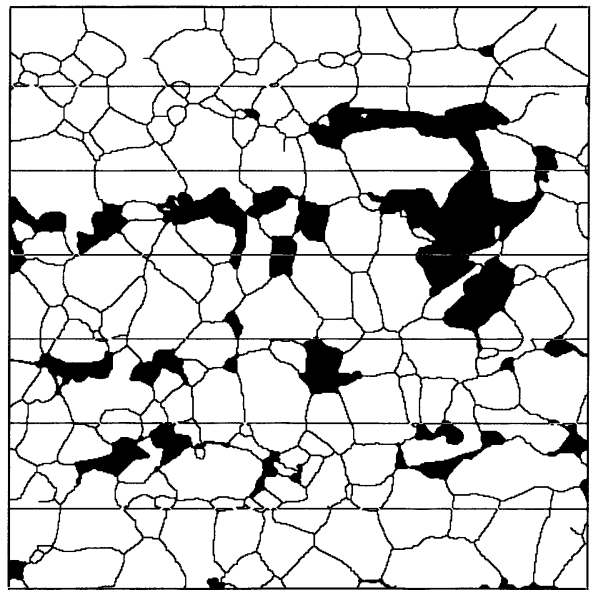

Fig. 9.

Fig. 8. - Final image.

Fig. 9. - Horizontal intercept grid.

\section{Validation}

This stage of validation has been performed on a large number of steel microstructures. The first stage was to check whether the results of mean intercept obtained by this automated treatment were in good agreement with operator measurements or not; the results are comprised within the uncertainty of measurement handled by operators. 


\section{Sollac \\ C.R.D.M.}

METHODES PHYSIQUES DINVESTIGATIONS

$\begin{array}{ll}\text { Date: } & 21 / 08 / 1996 \\ \text { Heure: } & 08: 36: 46\end{array}$

Référence ou $n^{\circ}$ d'étude:

Repère de l'échantillon:

Objectif utilisé:

(mesures en microns)

\begin{tabular}{|c|c|c|c|c|}
\hline $\begin{array}{c}\text { CHAMP } \\
\text { \% phase } \\
\text { carburee }\end{array}$ & $\begin{array}{c}\text { Intercept } \\
\text { horizontal }\end{array}$ & $\begin{array}{c}\text { Intercept } \\
\text { velical }\end{array}$ & $\begin{array}{c}\text { Intercept } \\
\text { moyen }\end{array}$ \\
\hline 1 & 3 & 11.88 & 12.40 & 12.13 \\
2 & 2 & 12.21 & 12.05 & 12.13 \\
3 & 3 & 7.87 & 7.93 & 7.90 \\
4 & 2 & 9.39 & 9.49 & 9.44 \\
5 & 2 & 11.82 & 11.16 & 11.48 \\
6 & 2 & 12.51 & 12.13 & 12.31 \\
7 & 3 & 10.64 & 10.68 & 10.66 \\
8 & 2 & 9.31 & 8.86 & 9.08 \\
9 & 3 & 13.10 & 13.36 & 13.23 \\
10 & 2 & 12.13 & 11.89 & 12.01 \\
\hline Moyenne & 2.40 & 11.09 & 11.00 & 11.04 \\
Ecart type & 0.52 & 1.71 & 1.73 & 1.71 \\
\hline
\end{tabular}

\begin{tabular}{|l|c|c|}
\hline ECHANTILLON & Moreme & Ecart lype \\
\hline Intercept horizontal & 10.79 & 7.39 \\
Intercept vertical & 10.72 & 7.41 \\
Intercept global & 10.75 & 7.40 \\
\hline
\end{tabular}

Précision en \% sur la moyenne de l'intercept global à 95\% (+/-) :

COTATION GRANULOMETRIQUE METHODES DES INTERCEPTS LINEAIRES

\section{STRUCTURE DE L'ECHANTILLON:}

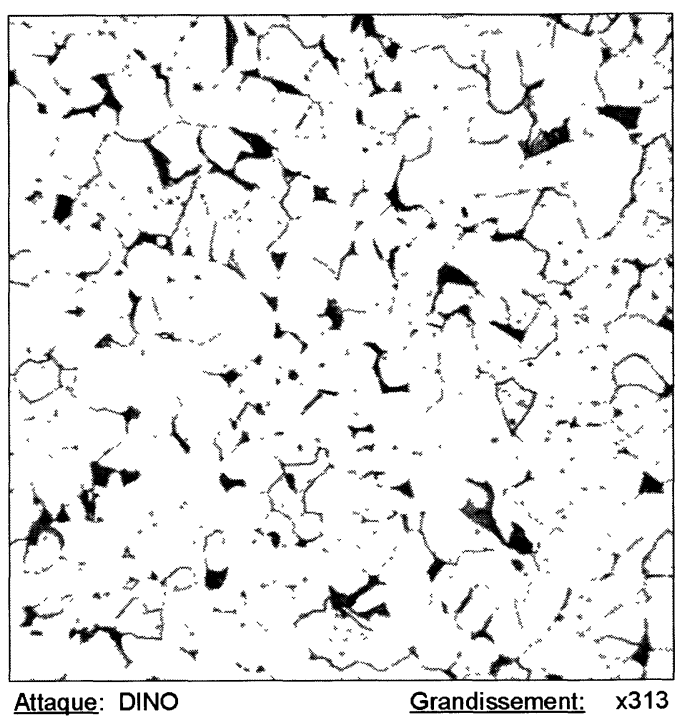

\begin{tabular}{|lc|}
\hline Norme NF A 04-102 \\
\hline Facteur de forme (int $\mathrm{H} /$ int $\mathrm{V}$ ) : & 1.01 \\
Indice de taille de grain $\mathrm{G}:$ & 9.79 \\
Diamètre moyen : & 11.88 \\
\hline
\end{tabular}

1.57
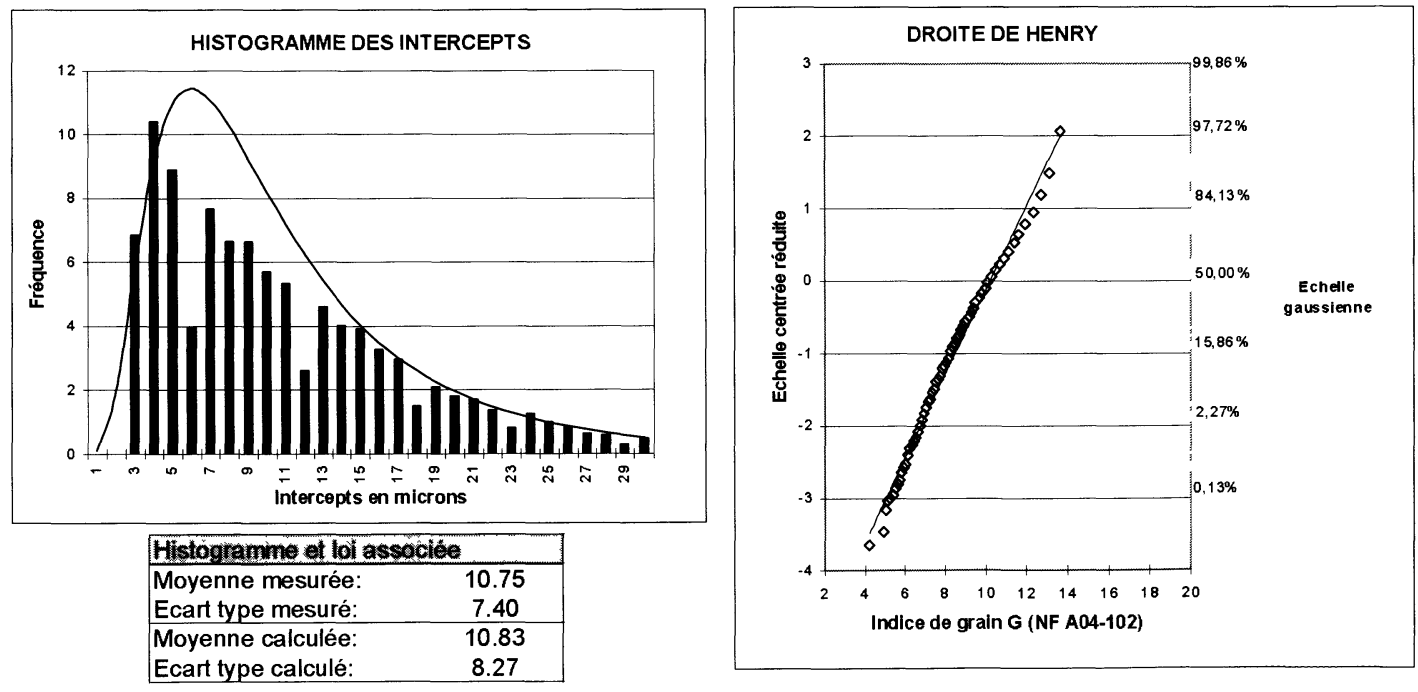

Fig. 10. - Standard results provided. 
A statistical study has been carried out to determine the number of treated images depending on the size of the grid necessary to reach a given accuracy. The same statistical approach has been performed so as to assess the effect of preparation and etching on the results. This led to the definition of an internal standard of preparation described in our quality control system which insures the statistical reproductibility of the results. Some questions also arose from this study: how to perform sampling on a sheet for grain size measurement knowing that the heterogeneity can reach locally 10 to $15 \%$ in relative value of the mean intecept? The effect of magnification which can lead to variation up to $15 \%$ in relative value on the intercept size will be smoothed by a zoom lens mounted on the optical microscope. It will allow continuous variations of magnification with the mean intercept.

\section{Results}

The results are presented on a standard data sheet shown in Figure 10. The overall average linear intercept, the related standard deviation and the relative accuracy of the mean intercept which can reach $1 \%$ or $2 \%$ are available. The elongation of the structure is also computed as well as the standard deviation of the characterized images' mean intercept. This latter information can be correlated to the level of heterogeneity of the microstructure. A descriptive statistical approach is also provided so as to make comparisons more easily.

\section{Conclusions}

The automatic grain size measurement of the microstructures met in the steels produced by SOLLAC is a success for at least three years. It took part in a remarkable achievement: the physical model describing the mechanical properties can predict with a level of accuracy never yet reached $(15 \mathrm{MPa})$ the mechanical properties of our steels. The accuracy of the grain size measurement also leads to the detection of differences between structures opening new way of understanding and research.

\section{References}

[1] Serra J., Image Analysis and Mathematical Morphology (Academic Press, 1982).

[2] Coster M. et Chermant J.L., Précis d'analyse d'images (Presses du CNRS, 1989).

[3] Underwood E.E., Quantitative Stereology (Addison-Wesley Publishing Company, 1970).

[4] Exner H.E. and Hougardy H.P., Quantitative Image Analysis of Microstructures (DGM informationsgesellschaft Verlag, 1988).

[5] DeHoff R.T. et Rhines F.N., Microscopie quantitative (Masson et Cie, 1972). 